\title{
HYDROCELE FOLLOWING PLACEMENT OF A VENTRICULOPERITONEAL SHUNT
}

\author{
CASE REPORT
}

JOSE SENA CALVARIO * - ELISEU PAGLIOLI NETO **

\begin{abstract}
SUMMARY - The authors report the case of a two years old patient with hydrocele after
\end{abstract} ventriculoperitoneal shunt procedure.

Hidrocele após colocação de derivação ventriculo-peritoneal: registro de caso.

RESUMO - Os autores registram um caso de hidrocele surgida após colocação de shunt ventriculo-peritoneal em paciente com dois anos de idade.

Numerous abdominal complications have been reported subsequent to ventriculoperitoneal shunting procedures for the treatment of hydrocephalus 1 . Intra abdominal complications of peritoneal shunts include: perforation of the gallblader; inguinal hernia, ascites and cyst formation; intestinal volvulus and obstruction, perforation of a viscus, or to the outside; spread of neoplasm or infection to the peritoneal cavity $\mathbf{2 , 8 , 9}$.

Although a variety of complications have been well documented, there has been little attention given in the literature to the association with hydrocele illustrated in the following case.

\section{CASE REPOR'T}

FH, a two year old male patient, had undergone repair for hydrocephalus; a ventriculoperitoneal shunt was placed at thirty days using a Raimondi middle-pressure perltoneal catheter. The course was uneventful; on routine pediatric evaluation swelling of the scrotum was noted without evidence of inguinal bulge (Fig. 1). Abdominal roentgenogram revealed the cacheter tip in the right scrotum (Fig. 2), and uncomplicated surgical repair and shunting repositioning followed.

\section{COMMENTS}

Ventriculoperitoneal shunts are the procedure of choice in the treatment of hydrocephalus at our institution. We present an unusual complication of this procedure.

The first cerebrospinal fluid (CSF) shunt to the peritoneal cavity is credited to Ferguson 3 who in 1898 laid a silver wire in a fistulous tract from the lumbar subarachnoid space at the body of L-5. This method and all other early attempts failed, and it was not until about 25 years ago that some success was reported 5,6 . When the Spitz-Holter valve and suitable catheter material became available, the technique

* Hospital Mãe de Deus, Porto Alegre; ** Instituto de Neurocirurgia, Santa Casa de Misericórdia, Porto Alegre.

Dr. José Sena Calvario - Rua F'ernandes Vieira 569 apto. $24-90210$ Porto Alegre RS Brasil 


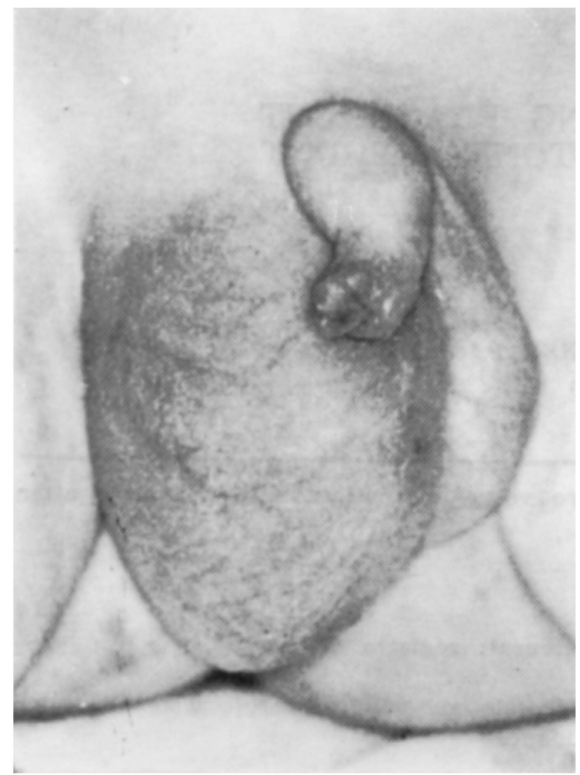

Fig. 1 - Patient F'H: rigth hydrocele.
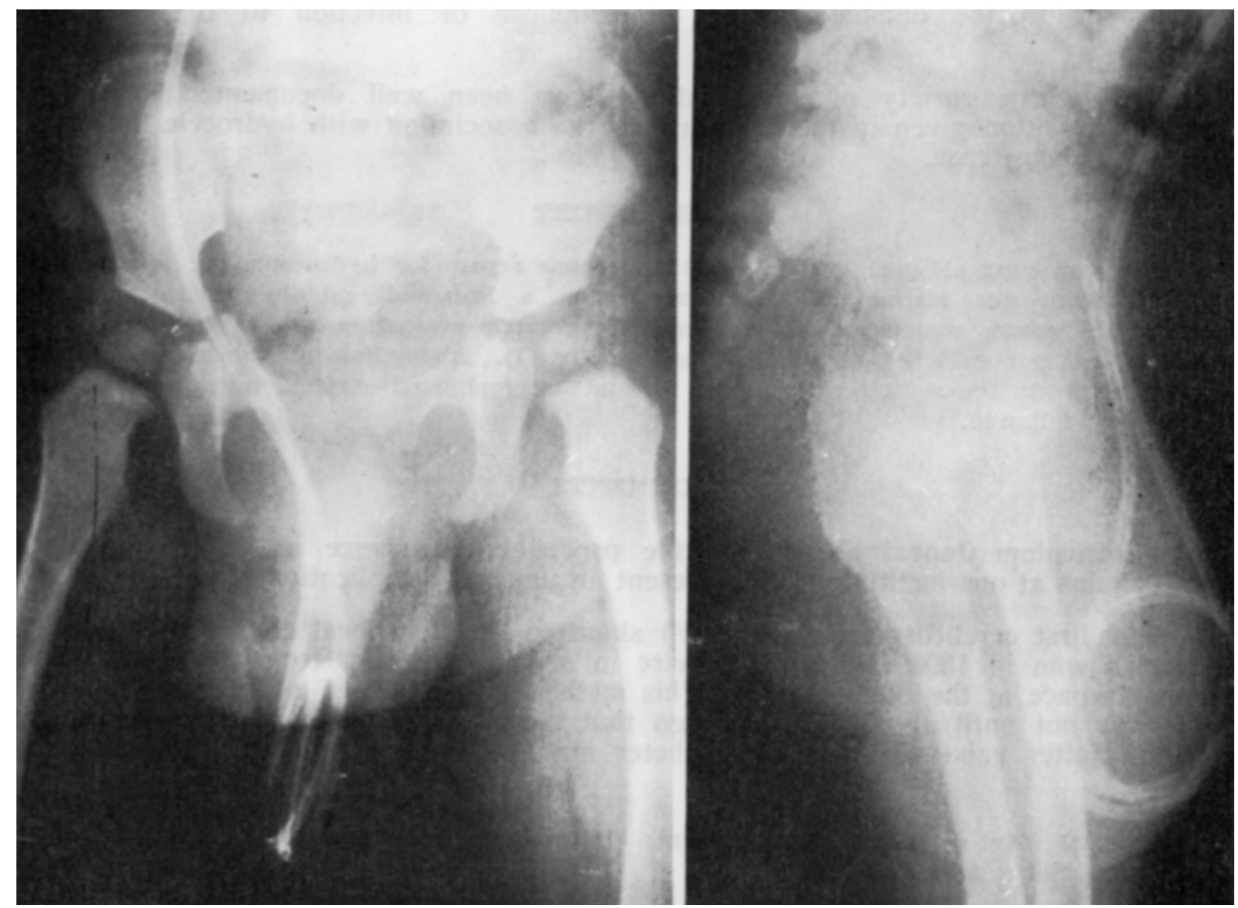

Frig. 2 - Patient FH: X-ray films showing the catheter tip in the right scrotum. 
of ventriculovenous shunting became popular. It was soon learned that serious complications with ventriculoatrial shunt were not infrequent and, in 1967, attention was again turned to the peritoneal cavity. The history of the evolution of ventricular shunting for hydrocephalus is largely related to efforts in preventing the complications of shunting. Until a time in which pharmacologic control of CSF production will be achieved, the treatment of hydrocephalus will rely mainly on the establishment of artificial conduits for the venting of CSF from the ventricular system. Such devices have been fraught with mechanical and biological complications.

Hydrocele as a complication of a peritoneal shunt has been cited as an infrequent finding in one reported earlier series 7. Recently a $26 \%$ incidence of clinical inguinal hernia has been noted to occur on the average within seven months after the initial ventriculoperitoneal shunt procedure 4. These findings suggest that particular attention should be given to subtle signs of inguinal hernia or increasing hydrocele formations both before and specially after peritoneal shunting. In particular, the inguinal and scrotal areas should be regulary observed by all those responsible for evaluating peritoneal shunt functioning.

\section{REFERENCES}

1. Adeloye A - Spontaneous extrusion of the abdominal tube through the umbilicus complicating peritoneal shunt for hydrocephalus: case report. J Neurosurg 38:758, 1973.

2. Ames RH - Ventriculo-peritoneal shunts in the management of hydrocephalus. J Neurosurg $27: 525,1967$.

3. Ferguson AH - Intraperitoneal diversion of the cerebrospinal fluid in cases of hydrocephalus (review). NY Med J 67:902, 1898.

4. Grosfeld J - Intra abdominal complications following ventriculoperitoneal shunt procedures. Pediatrics $54: 791,1974$.

5 Jackson IJ, snodgrand SR - Peritoneal shunts in the treatment of hydrocephatus and increased intracranial pressure: a 4-year survey of 62 patients. $J$ Neurosurg 12:216, 1955 .

6. Matson DD - Current treatment of infantile hydrocephalus. N Engl J Med 255:333, 1956.

7. Murtagh F, Lehmann $\mathrm{R}-$ Peritoneal shunt in the management of hydrocephalus. J Am Med Assoc 202:1010, 1967.

8. Patel $\mathrm{CD}$, Matlanb $\mathbf{H}$ - Vaginal perforation as a complication of ventriculoperitoneal shunt: case report. J Neurosurs 38:761, 1973.

9. Portnoy HD, Croissant PD - Two unusual complications of a ventriculoperitoneal shunt: case report. J Neurosurg 39:775, 1973. 